\title{
Editorial
}

\section{Robin SKeates}

\section{Durbam University, UK}

Welcome to the first issue of the European Journal of Archaeology for 2016. Here, we present six general articles and ten book reviews. Below, I summarize and evaluate their significance to the archaeology of Europe.

Karl-Johan Lindholm and John Ljungkvist examine the spatio-temporal patterning of animal remains recovered from first millennium $\mathrm{AD}$ archaeological contexts such as settlements, graves, and pitfall systems (i.e. hunting traps) in Sweden. They chart an expansion of human settlement into the forested inland region of Scandinavia, which they suggest was aimed at the more intensive exploitation of valued animal resourcesespecially furs of bear and lynx and antlers of elk, red deer, and wild reindeer. This trend was arguably connected to the development of extensive pre-Viking Scandinavian and Baltic exchange networks. It also resulted in a substantial reduction in populations of large carnivores and herbivores. From an archaeological perspective, the key to the success of this original and persuasive article is the authors' use of an inter-regional comparative approach; but it also makes a rare and important contribution to the on-going nature conservation debate.

Rainer Atzbach reviews the archaeological evidence for the practice of Christian prayer in late medieval and post-medieval times in northern and central Europe. Relevant material remains extend from ecclesiastical buildings to corpses buried with their arms in praying positions to personal objects such as rosaries, pilgrim badges, and prayer books. With reference to this varied evidence, Atzbach argues that prayer may have evolved from a collective act to a more diversified, individual one after AD 1300, paving the way for both the Protestant and the Catholic Reformations in the sixteenth century. In this way, Atzbach usefully draws attention to the somewhat neglected subject of the material manifestations of prayer (certainly in a medieval context), but also leaves the door open for future studies to consider related issues, such as the relationship between prayer and magic and the gendering of prayer objects.

Rachel Askew seeks to move beyond the question of whether (medieval) castles in England were originally built for defence or social status. Instead, using a biographical and experiential approach, she emphasises the changing significances and interactions of post-medieval castles over time, focussing on the Royalist occupation of Sandal Castle in Yorkshire during the English Civil Wars. This castle was fortified during the first Civil War (AD 1642-1646), arguably not because of its architectural strength or strategic location, but because of its symbolic associations with the past, including the Battle of Wakefield won by Richard III in front of its walls in 1460. In this way, Askew cuts through the medieval/post-medieval divide that has dogged castle studies, whilst also proposing an original notion of the castle as war memorial.

Can Aksoy is an archaeologist and Ziyacan Bayar a graphic designer. Based on their conference paper which won the European Association of Archaeologists' Student 
Award in 2014, they describe here their collaborative research at Aslihanlar-the site of a decisive battle fought between Turkish and Greek forces in 1922 during the Turkish War of Independence. Their work has involved not only an archaeological survey of the site, the study of documentary sources, and the recording of oral traditions, but also the experimental design of a visual storytelling space and interactive map intended to collect multiple historical perspectives on the battle, which they hope to make accessible to the public online. Helpfully, the authors discuss the theoretical and practical challenges of their research. Overall, this article represents a valuable trans-disciplinary contribution to both battlefield archaeology and public archaeology.

Tiina Äikäs and Marte Spangen archaeologically examine the material culture left at a sample of six Sami offering sites in Finland and Norway in order to evaluate continuities and discontinuities in the users and uses of these sacred sites. Traditionally, the Sami people left subsistence-related animal offerings and special artefacts at these sites for religious purposes; whereas modern objects, ranging from coins to a stick carved with runes, have been left by local (Sami) people, tourists, and neo-pagans for diverse reasons. Although the sacredness and authenticity of these modern practices can be questioned, the authors argue that heritage managers and archaeologists should not simply dismiss them as irrelevant to the values of those offering sites, and should seek to understand the multi-vocal discourses involved. In sum, this article offers a new and nuanced perspective on the sensitive issue of neo-pagan practices at old (and new) sacred sites.

The issue of authenticity is also discussed by Sally Foster and Neil Curtis in their ground-breaking article which explores the biographies of replicas of archaeological material made for and by antiquarians and museums between c. 1850 and 1914. With particular reference to replicas of early medieval sculpture from the British Isles, they show how a series of social networks determined why, when, and in what circumstances such objects (and the things that they copied) were valued. Foster and Curtis also ask us to think again about the value of these objects today and appeal to researchers, heritage managers, and museum curators to ensure their future survival. In this way, they succeed in their goal of narrowing the 'gulf between cultural theory and curatorial practices'.

In our reviews section, we start with encouraging comments on a set of three new books discussing archaeological theory and methods. Next, Umberto Albarella offers warm praise for Brian Hayden's latest book on feasting, despite expressing some reservations about its single interpretative approach. Andrew Jones provides an excellent commentary on two books about memory and, in the process, sets the agenda for future studies of memory by archaeologists. John Chapman delivers a critical review of the latest book on the archaeology of salt. The following reviews cover books on: the social construction of domestic space, social stratification and the state in the Iberian peninsula, Bronze Age deposition sites in Sweden, and textiles and basketry from Swiss Neolithic and Bronze Age lake dwellings. We then end with praise for two important new volumes on the Neolithic.

If you are interested in submitting an article on any aspect of European archaeology, or have recently published a book that you would like us to review, do please get in touch with a member of our editorial team or visit us on http://www.maney.co.uk/index. php/journals/eja/. 